\title{
Experimental Test of Morphological Stability Theory for a Planar Interface During Rapid Solidification
}

\section{Citation}

Hoglund, David E., Michael O. Thompson, and Michael J. Aziz. 1998. Experimental test of morphological stability theory for a planar interface during rapid solidification. Physical Review Series B 58(1): 189-199.

\section{Published Version}

http://dx.doi.org/10.1103/PhysRevB.58.189

\section{Permanent link}

http://nrs.harvard.edu/urn-3:HUL.InstRepos:2798517

\section{Terms of Use}

This article was downloaded from Harvard University's DASH repository, and is made available under the terms and conditions applicable to Other Posted Material, as set forth at http:// nrs.harvard.edu/urn-3:HUL.InstRepos:dash.current.terms-of-use\#LAA

\section{Share Your Story}

The Harvard community has made this article openly available.

Please share how this access benefits you. Submit a story.

\section{Accessibility}




\title{
Experimental test of morphological stability theory for a planar interface during rapid solidification
}

\author{
David E. Hoglund \\ Division of Engineering and Applied Sciences, Harvard University, Cambridge, Massachusetts 02138 \\ Michael O. Thompson \\ Department of Materials Science and Engineering, Cornell University, Ithaca, New York 14853 \\ Michael J. Aziz* \\ Division of Engineering and Applied Sciences, Harvard University, Cambridge, Massachusetts 02138
}

(Received 2 October 1997)

\begin{abstract}
We report a parameter-free test of the theory predicting the critical solute concentration that destabilizes a planar solid-liquid interface in the high-velocity regime where nonequilibrium interface kinetics are important. Rapid solidification following pulsed laser melting was used to make metastable solid solutions of silicon-tin. Rutherford backscattering spectrometry and transmission electron microscopy were used to measure the breakdown concentration. Samples remained microsegregation free with near perfect crystallinity at tin concentrations up to 10 times the maximum equilibrium solubility and 100 times that predicted by linear stability theory with local interfacial equilibrium. These measurements, covering velocities from 1 to $10 \mathrm{~m} / \mathrm{s}$, agree with the predictions of linear stability theory when the latter incorporates a velocity-dependent partition coefficient and a thermodynamically consistent kinetic liquidus, and contains no adjustable parameters. We also report a systematic increase of the breakdown concentration with increasing deviation from steady-state conditions, which is not addressed by current stability theories, parametrized by the concentration gradient just prior to breakdown. [S0163-1829(98)07117-3]
\end{abstract}

\section{INTRODUCTION}

The supersaturation of substitutionally sited elements in silicon following pulsed laser melting and rapid solidification has been studied extensively. ${ }^{1-8}$ The attainable degree of supersaturation is strongly dependent on the interface velocity because deviations from equilibrium become more significant as the solidification velocity increases. A variety of mechanisms limiting solubility has been identified, but the most common is a morphological instability of the planar solid-liquid interface during solidification. This mechanism was identified for $\mathrm{Sn}$ in $\mathrm{Si}$ by White et al., ${ }^{9}$ who observed a cellular solidification microstructure at high concentrations. It has been observed not only for many other low-solubility elements in $\mathrm{Si}^{9,10}$ but also for high-solubility elements such as Ge. ${ }^{11,18,12}$

During steady-state solidification of a single-component melt in local interfacial equilibrium, a planar solid-liquid interface will remain stable as long as heat is removed through the solid. The solid stays below the melting temperature, the interface at the melting temperature, and the liquid above the melting temperature.

For a two-component melt in local interfacial equilibrium, Tiller et $a l .{ }^{13}$ analyzed the "constitutional supercooling", effect of solute preferentially partitioning into the liquid. They showed that for any straight-line liquidus and any given interface velocity, there exists a critical concentration of solute in the bulk liquid such that the interface is unstable. Solute rejected by the interface creates a concentration gradient in the liquid layer next to the interface. The concentration gradient causes a region in the liquid ahead of the interface to be undercooled with respect to the composition-dependent liquidus temperature, despite being at a higher absolute temperature than the interface.

Mullins and Sekerka ${ }^{14}$ included the effect of capillarity in a linear perturbation analysis of interface stability. They started their analysis with an unperturbed planar interface in local equilibrium moving at a constant velocity. Then they calculated the time dependence of the amplitude of an infinitesimal sinusoidal-shaped perturbation imposed on the interface. Because the perturbation curves the interface, capillarity has a stabilizing effect, especially at high solidification velocities. The higher the velocity, the less time there is for lateral diffusion of solute; long-wavelength perturbations no longer have sufficient time to form. Short-wavelength perturbations do have time to form, but the smaller the wavelength, the higher the curvature and the more strongly capillarity resists instabilities. Thus, for a melt with a given bulk solute concentration, there is a velocity above which a planar interface is always stable. This is the absolute stability limit ${ }^{8}$

$$
C_{\infty}=\frac{k^{2} T_{M} \Gamma v}{(k-1) m D},
$$

where $C_{\infty}$ is the critical bulk concentration in the liquid, $k$ the partition coefficient (ratio of the solute concentration in the growing solid to that in the liquid at the interface), $T_{M}$ the melting point of pure solvent, $\Gamma$ the capillarity constant (interfacial tension divided by the latent heat of fusion), $v$ the interface velocity, $m$ the slope of the equilibrium liquidus (assumed to be a straight line), and $D$ the diffusivity of solute in the bulk liquid. 


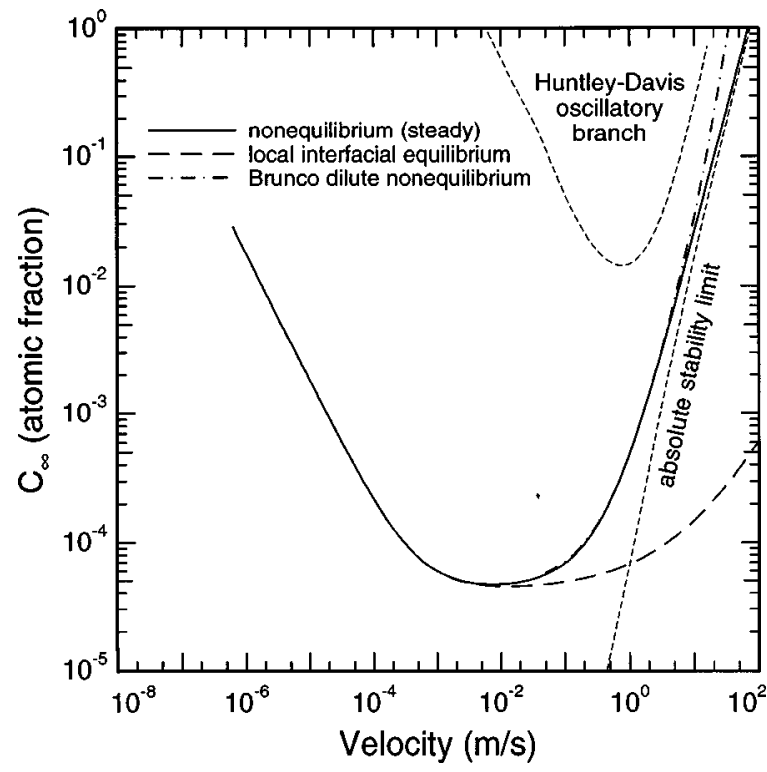

FIG. 1. Predicted neutral stability curves for Si-Sn (001). A planar interface is unstable above the neutral stability curve. The absolute stability limit was calculated using Eqs. (1), (2), and (3).

The Mullins-Sekerka analysis assumes local equilibrium at the interface. This assumption is most likely to break down at velocities where Eq. (1) is most likely to be valid. The interface stability limit is strongly influenced by nonequilibrium effects, particularly the suppression of partitioning ("solute trapping") (Ref. 15) during nonequilibrium solidification. Solute trapping is expected to stabilize the interface, and early tests of interface stability under nonequilibrium conditions ${ }^{3,5,16}$ did indeed show such stabilization. The degree of stabilization was unclear, however. The authors of these studies compared their data to the absolute stability limit, Eq. (1), except that they substituted the nonequilibrium partition coefficient for the equilibrium one. This modification to the Mullins-Sekerka theory ignores the thermodynamic constraint ${ }^{17}$ requiring a change in the effective liquidus slope with nonequilibrium trapping [see Eq. (3) below]. Additionally, as these studies did not involve direct measurements of velocity, the resulting values of $v$ and $k$ were only estimates based on heat-flow simulations using a value of the thermal conductivity of amorphous silicon that was poorly known at that time. ${ }^{18}$ As the predictions of Eq. (1) are very sensitive to uncertainties in $k$ and the value of $k$ inferred from solute trapping experiments is very sensitive to uncertainties in $v$, any agreement of theory with experiment must be considered fortuitous. These early results, however, can be considered as qualitative evidence that nonequilibrium effects stabilize the interface. Now that the kinetic undercooling function in pure ${ }^{19-21}$ and alloyed silicon ${ }^{22}$ and the solute trapping function for various dopants in silicon ${ }^{23-25,6,7}$ have been measured, it is possible to incorporate nonequilibrium effects accurately and systematically into stability theory.

Experiments support the so-called "continuous growth model without solute drag" ${ }^{25}$ for nonequilibrium interface kinetics during rapid solidification. For solute trapping in the dilute solution regime, the model gives

$$
k(v)=\frac{k_{e}+\left(v / v_{D}\right)}{1+\left(v / v_{D}\right)},
$$

where $k$ is the nonequilibrium partition coefficient, $k_{e}$ the equilibrium partition coefficient, $v$ the interface velocity, and $v_{D}$ a kinetic parameter called the diffusive velocity. Assuming a dilute solution, a straight-line equilibrium liquidus and solidus, and a solidification velocity much less than the maximum solidification velocity at infinite driving force, Boettinger and co-workers derived from the continuous growth model a simple expression ${ }^{17,26}$ for the slope of the kinetic liquidus,

$$
m(v)=m_{e}\left\{1+\frac{k_{e}-k(v)\left\{1-\ln \left[k(v) / k_{e}\right]\right\}}{1-k_{e}}\right\}
$$

where $m_{e}$ is the slope of the equilibrium liquidus. Substituting the partition coefficient of Eq. (2) and the liquidus slope of Eq. (3) into the Mullins-Sekerka result [not just Eq. (1), but rather the full solution] yields a thermodynamically consistent formulation of nonequilibrium linear stability theory. For any point in concentration-velocity space, one can calculate whether or not a planar interface is stable. Because each of the key parameters in the theory has been measured independently, the calculation has no free parameters. Typically, one calculates a neutral stability curve: the line in concentration-velocity space that separates the region of stable interface growth from unstable interface growth. The interface is stable below and unstable above the neutral stability curves presented in this paper, e.g., Fig. 1.

A fuller formulation of linear stability theory by Davis and co-workers ${ }^{27,28}$ allows for oscillatory solutions to the perturbation growth equation. This family of solutions, driven by a mechanism called the "solute pump," was identified by Coriell and Sekerka. ${ }^{29}$ As shown in Fig. 1, Huntley and Davis's calculations for the silicon-tin system ${ }^{28}$ show that the region of instability against oscillatory perturbations lies completely within the region of instability against nonoscillatory (steady) perturbations. Thus the steady branch defines the stability limit, and the simple stability calculation [Eqs. (2) and (3) substituted into the full Mullins-Sekerka equation] is quantitatively identical to Huntley and Davis's calculation.

Another formulation of linear stability theory by Brunco ${ }^{11}$ allows nondilute solutions and offers a novel treatment of what Brunco terms "nonequilibrium capillarity." Brunco's calculation for silicon-tin, ${ }^{11}$ also shown in Fig. 1, is quantitatively similar to Huntley and Davis's calculation. Breakdown in the silicon-tin system does not happen at a high enough concentration or at a small enough length scale to readily distinguish the theories.

$\mathrm{Cahn}^{30}$ extended the linear stability formalism to take into account the first and second derivatives with respect to interface orientation of the solute trapping function and of the interface mobility. Whereas the solute trapping function is known for many orientations, ${ }^{24,26}$ the interface mobility is known only for (001) (Ref. 31) and (111) (Refs. 21 and 32). Because certain terms in Cahn's analysis vanish for highly symmetric orientations such as (001) and (111) studied here and because Cahn concludes that other terms are expected to 
be important only for high concentrations, we do not expect anisotropy effects to be significant in the present study.

We reported ${ }^{33}$ a quantitative test of stability theory using tin-implanted silicon-on-sapphire (SOS) samples. However, the large number of extended defects in these samples not only made identification of the cell walls difficult, but also might have influenced the breakdown of the planar interface. Here we report similar measurements performed on bulk single-crystal silicon in the (001) and (111) orientations. By melting completely through the region damaged by the tin implant, we ensure a high-quality seed for subsequent solidification of the melt.

\section{EXPERIMENTAL TECHNIQUE}

Wafers of (001) silicon were implanted with 165 or 120 $\mathrm{keV}{ }^{120} \mathrm{Sn}^{+}$at doses of $3 \times 10^{15}-2 \times 10^{16} \mathrm{~cm}^{-2}$. Most samples were also lightly implanted with a pair of boron implants, typically $100 \mathrm{keV}{ }^{11} \mathrm{~B}^{+}$at $3 \times 10^{15} \mathrm{~cm}^{-2}$ and 200 $\mathrm{keV}{ }^{11} \mathrm{~B}^{+}$at $5 \times 10^{15} \mathrm{~cm}^{-2}$, to aid in ascertaining melt depths in cross-sectional transmission electron microscopy (TEM). The wafers of (111) silicon were implanted to higher doses of tin $\left(1,2\right.$, and $\left.4 \times 10^{16} \mathrm{~cm}^{-2}\right)$, but did not receive the additional boron implant.

Most samples were melted with a $30 \mathrm{~ns}$ full width at half maximum (FWHM) XeCl (308 nm) excimer laser pulse. Intense radiation absorbed at the sample surface causes melting. When the laser pulse ends, the sample solidifies quickly as the heat flows from the surface into the bulk. The velocity depends on pulse energy, but only indirectly. The direct factor is the thermal gradient between the melt and the bulk of the sample (still at room temperature at the end of the laser pulse). To attain lower velocities, we preheated samples from the back side using a continuous-wave $\mathrm{CO}_{2}$ laser just before firing the excimer. As the $\mathrm{CO}_{2}$ heated the sample, a reduced thermal gradient was established between the molten region and the bulk substrate; additionally, the thermal conductivity of the bulk is reduced at high $T$. To attain higher velocities, we melted some samples using pulses from a Nd:YAG laser (1064 nm) with a $3 \mathrm{~ns}$ FWHM. In situ reflectivity measurements with a low-powered $\mathrm{Ar}^{+}$probe laser $(488 \mathrm{~nm})$ exploited the difference in reflectivity between solid and liquid to measure melt durations.

The spatial homogeneity of the melting pulse is crucial to the success of the experiment. We tuned the excimer laser using a beam profiling camera until the camera measured a $3 \% \mathrm{rms}$ deviation in intensity over the area of the sample. We quantified the effect of this variation on our measurements by doing statistics on a large number of split-probe reflectivity measurements. Comparing melt durations measured simultaneously at two different points on the sample surface, we observed a variation of $\pm 5 \mathrm{~ns}$, in melt duration at typical laser fluences, which corresponds to $\pm 4 \%$ in fluence. The $\mathrm{CO}_{2}$ beam was expanded so that any inhomogeneities caused no larger melt duration variability than for the $\mathrm{XeCl}$ laser alone.

After solidification, tin concentration-depth profiles were measured using Rutherford backscattering spectrometry. Because the presence of normally substitutional dopants off lattice sites has been correlated with interface breakdown, ${ }^{16}$ we also performed an ion channeling analysis. We initially as- sumed that the interface broke down at the depth where the concentration of nonsubstitutional tin became appreciable. For several samples, we examined the microstructure directly using cross-sectional TEM. In addition to verifying the depth of breakdown, the microscopy allowed us to verify that the breakdown morphology was cellular.

Microscopy also yielded information about the maximum penetration of the melt front for any particular sample. Following the example of Narayan et al. ${ }^{34}$ we used a boron implant to create a marker layer visible in TEM. According to Narayan et al., the boron implant creates point defects that condense to form dislocation loops deep in the sample. During laser melting, loops that melt disappear forever; loops that do not melt coarsen to a size large enough to be observed in TEM (several hundred angstroms). The maximum melt depth is therefore the depth at which the sample changes from having no loops to having many loops. Because the maximum melt depth is sharply defined and because dislocations cannot have free ends inside the crystal, loops that partially melt seed dislocations that terminate on the surface. Narayan et al. occasionally saw such dislocations, providing strong confirmation that dislocation loops exist in the unmelted solid right up to the maximum melt depth. We did not attempt to image individual loops and relied on the work of Narayan et al. for the interpretation in terms of dislocation loops. In our micrographs, the region of the boron implant appears mottled, as opposed to the even gray of the region that melted and of the Si beyond the boron implant range.

\section{DATA ANALYSIS}

In this experiment, we measured the solidification velocity and breakdown concentration at the onset of interface instability, and then compared the values to the calculated neutral stability curve. Values for the parameters required for the interface stability calculation ${ }^{32,33,36-41}$ are given in Table I. Values for the parameters required for the heat flow simulations ${ }^{35,36,38,42-45}$ are given in Tables II and III.

\section{A. Solidification velocity}

For these samples, the melt duration as a function of laser fluence was very close to that of pure silicon. Consequently, we used well-calibrated heat-flow simulations of pulsed laser melting of pure silicon ${ }^{46}$ to determine melt depths and solidification velocities. The effect of an amorphous surface layer created during ion implantation has been studied in experiments on self-implanted silicon, and the optical and thermophysical properties of amorphous silicon are well tested. ${ }^{46}$ Ion channeling measurements show that the top $160 \mathrm{~nm}$ is amorphous for a $165 \mathrm{keV}$ implant, although the exact thickness is not crucial. Plots of velocity as a function of melt duration for simulations with various thickness amorphous layers, as in Fig. 2, are essentially identical for all thicknesses of the amorphous Si layer.

Assessing the effects of alloying due to implantation is more complicated. Alloying can affect the applicability of heat-flow simulation in two ways. The first is by changing the optical properties. Jellison et al. ${ }^{47}$ have measured the optical properties of heavily doped silicon $(0.6$ at. \% in the near surface region for samples implanted with boron, around 
TABLE I. Parameters for interface stability calculation. Note that the extrapolations were made in the original papers.

\begin{tabular}{|c|c|c|}
\hline Symbol & Value & Parameter \\
\hline$D$ & $2.5 \times 10^{-4} \mathrm{~cm}^{2} / \mathrm{s}$ & Diffusivity of tin in liquid silicon ${ }^{a}$ \\
\hline$v_{D}$ & $17 \mathrm{~m} / \mathrm{s}$ & Diffusive velocity $^{\mathrm{a}}$ \\
\hline$G_{L}$ & $2 \times 10^{4} \mathrm{~K} / \mathrm{m}$ & $\begin{array}{l}\text { Thermal gradient in the liquid (heat-flow } \\
\text { simulations) }\end{array}$ \\
\hline$G_{S}$ & & $\begin{array}{l}\text { Thermal gradient in the solid } \\
G_{S}=V L_{M} / K_{S}=1.9 \times 10^{8} \mathrm{~K} / \mathrm{m}(\text { at } 1 \mathrm{~m} / \mathrm{s})\end{array}$ \\
\hline$K_{L}$ & $140 \mathrm{~W} /(\mathrm{K} \mathrm{m})$ & Thermal conductivity of the liquid at melting point ${ }^{\mathrm{b}}$ \\
\hline$K_{S}$ & $22 \mathrm{~W} /(\mathrm{K} \mathrm{m})$ & Thermal conductivity of the solid at melting point ${ }^{\mathrm{b}}$ \\
\hline$T_{M}$ & $1685 \mathrm{~K}$ & Melting temperature of pure silicon ${ }^{\mathrm{c}}$ \\
\hline$k_{e}$ & 0.016 & Equilibrium partition coefficient $^{\mathrm{d}}$ \\
\hline$m_{e}$ & $-460 \mathrm{~K}$ & $m_{e}=(1-k) R T_{M}^{2} / L_{M}$ \\
\hline$L_{M}$ & $4.19 \times 10^{9} \mathrm{~J} / \mathrm{m}^{3}$ & Latent heat of fusion at melting temperature $\mathrm{e}^{\mathrm{e}}$ \\
\hline
\end{tabular}

Crystal-melt interfacial tension

\begin{tabular}{lcrrr} 
Symbol & Measurement & Undercooling & Extrapolated to $T_{M}$ & \multicolumn{1}{c}{ Reference } \\
\hline$\gamma$ & $0.36 \mathrm{~J} / \mathrm{m}^{2}$ & $285 \mathrm{~K}$ & Not extrapolated & Crystal nucleation $^{\mathrm{f}}$ \\
$\gamma$ & $0.38 \mathrm{~J} / \mathrm{m}^{2}$ & $350 \mathrm{~K}$ & $0.45 \mathrm{~J} / \mathrm{m}^{2}$ & Crystal nucleation $^{\mathrm{g}}$ \\
$\gamma$ & $0.438 \mathrm{~J} / \mathrm{m}^{2}$ & $420 \mathrm{~K}$ & $0.61 \mathrm{~J} / \mathrm{m}^{2}$ & Crystal nucleation $^{\mathrm{h}}$ \\
\hline \hline
\end{tabular}

${ }^{\mathrm{a}}$ Reference 30 .

${ }^{\mathrm{b}}$ Reference 32 .

${ }^{\mathrm{c}}$ Reference 33 .

${ }^{\mathrm{d}}$ Reference 34 .
${ }^{\mathrm{e}}$ Reference 35 .

${ }^{\mathrm{f}}$ Reference 36.

${ }^{\mathrm{g}}$ Reference 37.

${ }^{\mathrm{h}}$ Reference 38 .
$1.0 \%$ for samples implanted with arsenic) and find that doping has a small effect for $308 \mathrm{~nm}$ radiation. This bounds the effect for our samples. Given the high absorption coefficient for the $308 \mathrm{~nm}$ excimer laser, the optical properties of the sample are determined by only the top $20 \mathrm{~nm}$ of the sample. Because our implants were rather deep, the concentrations near the surface are low: about $1 \%$ for tin and $0.01 \%$ for boron. Therefore, we do not expect large changes in optical properties. The second possible effect of alloying on the results of the heat-flow simulations is by changing the thermophysical properties (latent heat or thermal conductivity) of the sample. Measurements on $\mathrm{Si}-\mathrm{As}$ by Kittl et al. ${ }^{48}$ show no difference in latent heat for $0 \%, 4 \%$, and $9 \%$ As and therefore we should not expect a significant change for our samples, which have up to $\sim 2 \% \mathrm{Sn}$. We have no data on the effect of alloying on the thermal conductivity. However, the effectiveness of the substrate as a heat sink is dominated by the reduced thermal conductivity of the crystal at high temperature. We believe it highly unlikely that alloying induces large changes in thermal conductivity at high temperatures where phonon scattering determines thermal conduction. We conclude that the optical and thermophysical properties of our samples are not likely to be changed substantially by alloying.

The combined result of these effects was small, but observable in our measurements. For a given implant, the melt duration as a function of incident laser fluence ${ }^{49}$ was reproducible with minimal noise. However, for different implants,

TABLE II. Parameters for heat-flow simulation.

\begin{tabular}{lllll}
\hline \hline Thermophysical property & \multicolumn{1}{c}{ Units } & Liquid & Amorphous & Crystal \\
\hline Melting temperature & $\mathrm{K}$ & & $1430^{\mathrm{a}}$ & $1685^{\mathrm{b}}$ \\
Latent heat of fusion & $\mathrm{J} / \mathrm{cm}^{3}$ & & $2986^{\mathrm{a}}$ & $4206^{\mathrm{c}}$ \\
Kinetic undercooling & $(\mathrm{m} / \mathrm{s}) / \mathrm{K}$ & & 0.267 & $0.0667^{\mathrm{d}}$ \\
Optical reflectivity at $308 \mathrm{~nm}$ & & $0.734^{\mathrm{e}}$ & $0.562^{\mathrm{e}}$ & $0.587^{\mathrm{e}}$ \\
Optical reflectivity at $1064 \mathrm{~nm}$ & & $0.777^{\mathrm{f}}$ & $0.4^{\mathrm{f}}$ & $0.32^{\mathrm{f}}$ \\
Optical absorption at $308 \mathrm{~nm}$ & $10^{6} \mathrm{~cm}^{-1}$ & $1.53^{\mathrm{e}}$ & $1.38^{\mathrm{e}}$ & $1.48^{\mathrm{e}}$ \\
Optical absorption at $1064 \mathrm{~nm}$ & $10^{3} \mathrm{~cm}^{-1}$ & $860^{\mathrm{f}}$ & $100^{\mathrm{f}}$ & $2^{\mathrm{f}}$ \\
Thermal conductivity & $\mathrm{W} /\left(\mathrm{K} \mathrm{cm}^{\mathrm{f}}\right.$ & $1.4^{\mathrm{g}}$ & $0.026^{\mathrm{h}}$ & \\
\hline
\end{tabular}

${ }^{\mathrm{a}}$ Reference 39 .

${ }^{\mathrm{b}}$ Reference 33 .

${ }^{\mathrm{c}}$ Reference 35 .

${ }^{\mathrm{d}}$ Reference 28 .
${ }^{\mathrm{e}}$ Reference 40.

${ }^{\mathrm{f}}$ Reference 41.

${ }^{\mathrm{g}}$ Reference 32 .

${ }^{\mathrm{h}}$ Reference 42. 
TABLE III. Temperature-dependent parameters for heat-flow simulation. The data for specific heat were converted from cal/(g K) using $2.33 \mathrm{~g} / \mathrm{cm}^{3}$ and $4.184 \mathrm{~J} / \mathrm{cal}$.

\begin{tabular}{cccc}
\hline \hline $\begin{array}{c}\text { Temperature } \\
(\mathrm{K})\end{array}$ & $\begin{array}{c}\text { Specific heat } \\
(\text { all phases })^{\mathrm{a}}\end{array}$ & $\begin{array}{c}\text { Temperature } \\
{\left[\mathrm{J} /\left(\mathrm{K} \mathrm{cm}^{3}\right)\right]}\end{array}$ & $\begin{array}{c}\text { Thermal } \\
\text { conductivity } \\
(\text { crystal })^{\mathrm{b}} \\
{[\mathrm{W} /(\mathrm{K} \mathrm{cm})]}\end{array}$ \\
\hline 273 & 1.609 & 273 & 1.68 \\
& & 300 & 1.48 \\
& & 350 & 1.19 \\
373 & 1.794 & 400 & 0.989 \\
473 & 1.920 & 500 & 0.762 \\
573 & 1.974 & 600 & 0.619 \\
673 & 2.013 & 700 & 0.508 \\
773 & 2.052 & 800 & 0.422 \\
873 & 2.091 & 900 & 0.359 \\
973 & 2.125 & 1000 & 0.312 \\
1073 & 2.159 & 1100 & 0.279 \\
1173 & 2.193 & 1200 & 0.257 \\
1273 & 2.232 & 1300 & 0.244 \\
1500 & & 1400 & 0.235 \\
1600 & 2.367 & 1500 & 0.227 \\
1690 & 2.392 & 1600 & 0.221 \\
1800 & 2.414 & 1685 & 0.220 \\
1900 & 2.461 & & \\
\hline \hline
\end{tabular}

${ }^{\mathrm{a}}$ Reference 35 .

${ }^{\mathrm{b}}$ Reference 32 .

the curves shifted within a band of width $\pm 5 \mathrm{~ns}$. Because we shall use a single calibration curve (for each laser) to convert melt duration to velocity, this implant-to-implant variation translates into an uncertainty in our reported velocities, which is included in our reported error bars. In fact, the actual error may be smaller. The calculation of error bars is based on using fluence as the independent variable. In actuality, we use melt duration to calculate solidification velocity. Melt duration is a more robust independent variable than incident laser fluence. For example, melt duration and velocity both depend on absorbed fluence and not reflected fluence; therefore, both will respond similarly to variations in surface reflectivity. As with the data of Fig. 2, melt duration is more robust with respect to some bulk properties too.

After collecting simulation data for solidification velocity as a function of melt duration, we tested our calibration curve experimentally. Consider the simulation of melt depth vs time shown in Fig. 3 as a solid line. The dashed line is the measured temporal profile of the laser pulse used in the simulation. As seen in the figure and confirmed by direct measurements on SOS samples, melting begins just after the laser pulse begins; solidification begins near the end of the laser pulse (35 ns) and proceeds at near constant velocity. These observations suggest the approximation shown in Fig. 3 as a dotted line. The approximation is rough for melting, but very good for solidification. As an equation, the approximation for solidification is

$$
\text { velocity }=\frac{\text { maximum depth }}{\text { melt duration }- \text { pulse duration }} .
$$

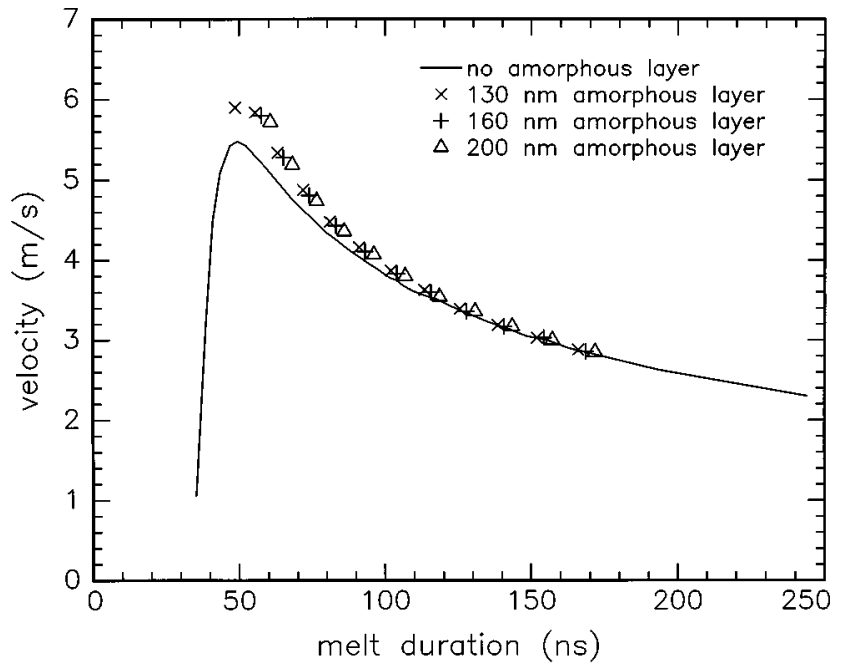

FIG. 2. Solidification velocity at $50 \mathrm{~nm}$ depth vs melt duration calculated by heat-flow simulation for 0-, 130-, 160-, and 200-nmthick surface amorphous layers. When there is no surface amorphous layer, a melt duration of 35 ns corresponds to a maximum melt depth of $50 \mathrm{~nm}$; hence, the velocity for this melt duration is identically zero.

These quantities are all measurable. The pulse duration is measurable and, for the $\mathrm{XeCl}$ laser, repeatable. Melt durations were measured in situ for each sample. The maximum melt depth was measured using cross-sectional transmission electron microscopy.

Figure 4 shows the results obtained by applying the approximation of Eq. (4) to five bulk silicon samples. The agreement is good, and so we use the simulation results to convert measured melt duration into velocity. For the $\mathrm{Nd}$ :YAG laser we proceeded similarly, but have only one experimental point to compare to the simulation. As shown in Fig. 4 (the left-hand side), the agreement is still good. The error bars are wider because the pulse spatial profile is Gaussian instead of a flat top. Therefore, even when the laser is well tuned, there is a distribution of fluences and a corresponding distribution of velocities.

Simulation does not work adequately for samples preheated using the $\mathrm{CO}_{2}$ laser. The $\mathrm{CO}_{2}$ pulse is too brief (about $1 \mathrm{~s})$ for us to readily measure the sample temperature, and it is not reproducible enough for us to develop a calibration. Therefore, each of these samples was examined in TEM to determine the maximum melt depth and Eq. (4) was used to calculate the velocity. Equation (4) should be accurate for these samples because preheating causes a longer melt duration and hence makes the calculated velocity less sensitive to the exact timing of melt initiation.

We now calculate error bars. Because velocity is determined from melt durations, the relative error in velocity scales with the relative error in melt duration. As discussed above, the contribution of spatial nonuniformity in the laser beam corresponds to $\pm 5 \mathrm{~ns}$ for a typical melt, and the contribution of variations in optical coupling from implant to implant was $\pm 5 \mathrm{~ns}$ as well. Based on repeated melting of clean bulk silicon, the instrumental error for the measurement system is negligible. The total uncertainty in melt duration is therefore $\pm 10 \mathrm{~ns}$. For a melt duration of typical 


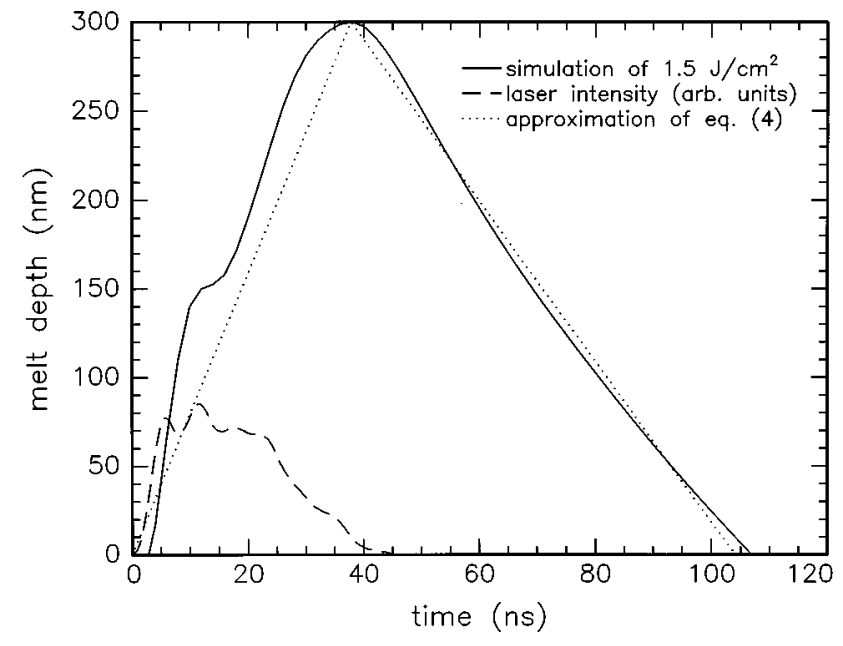

FIG. 3. Simulated melt depth vs time during $\mathrm{XeCl}$ pulsed laser melting of pure silicon with $100 \mathrm{~nm}$ amorphous silicon layer. The solid line is a heat-flow calculation based on the laser pulse profile shown as a dashed curve. The dotted line is the approximation implicit in Eq. (4).

length, the curve of velocity as a function of melt duration (Fig. 4) shows that an uncertainty of $\pm 10 \mathrm{~ns}$ translates to an uncertainty in solidification velocity of $\pm 10 \%$ for the $\mathrm{XeCl}$ laser and $\pm 20 \%$ for the Nd:YAG laser. This is a fair and accurate representation of the relative velocities reported here for the $\mathrm{Si}(001)$ samples. An additional factor contributing to uncertainty in the absolute velocities is the thermophysical parameters that go into the heat-flow simulations. This uncertainty adds roughly $\pm 10 \%$ potential systematic error in the reported velocities. Thus we calculate that an error of $\pm 20 \%$ in absolute velocity is a very conservative estimate for $\mathrm{XeCl}$ samples. $\mathrm{Nd}$ :YAG samples have a greater uncertainty due to the Gaussian spatial distribution of the laser pulse. Measurements of the intensity distribution show a variation equivalent to a variation in velocity of $\pm 1 \mathrm{~m} / \mathrm{s}$ between the center and the edges. This error is additive to those discussed above.

\section{B. Breakdown concentration}

In steady-state stability theory, $C_{\infty}$ in Eq. (1) is the concentration solute in the liquid very far from the interface. In steady state, this concentration is equal to the solute concentration in the solid adjacent to the interface. Because there is negligible diffusion in the solid after solidification, this concentration can be measured as a function of depth using Rutherford backscattering spectrometry (RBS). For the breakdown concentration, we used the RBS concentration-depth profile to determine the tin concentration at the depth where breakdown occurred. The first method for determining the depth at which breakdown occurred was to examine the sample in TEM. The cellular microstructure is easy to identify in cross-sectional samples. We did this for several samples and then correlated our observations with ion channeling to obtain a second method of determining breakdown depths.

Ion channeling techniques compare the dependence of backscattering yield on the crystallographic orientation of the

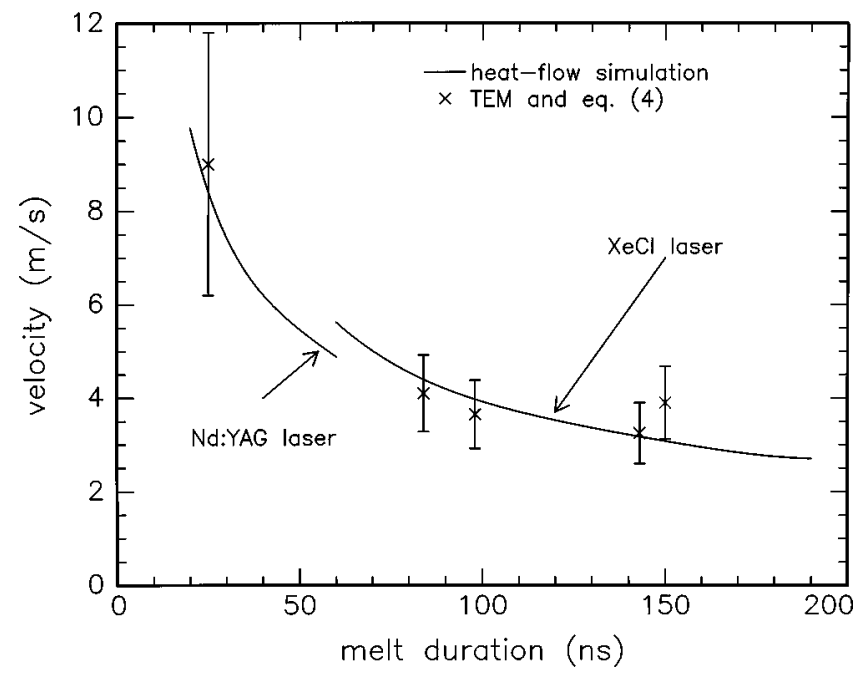

FIG. 4. Calibration curves for solidification velocity vs melt duration. The curve and point on the left are for the $5 \mathrm{~ns} \mathrm{Nd:YAG}$ laser pulse; the curve and points on the right are for the $30 \mathrm{~ns} \mathrm{XeCl}$ laser pulse.

incident ion beam. The effect is strong near the [001] channel of silicon. The yield data are analyzed by calculating the ratio of normalized yields $\chi$,

$$
\chi=\frac{\text { yield when aligned with channel }}{\text { yield at random orientation near channel }},
$$

as a function of depth. To achieve a representative random orientation, the sample is rotated during data collection. If $\chi$ as a function of depth is similar for the tin signal and the silicon signal, then the tin must be substitutional on the silicon lattice. For $\chi<1$, a first-order estimate ${ }^{50}$ for the fraction $S$ of solute that is substitutional on the solvent lattice is

$$
S=\frac{1-\chi^{\text {solute }}}{1-\chi^{\text {solvent }}}
$$

The equation is an estimate because it assumes a uniform spatial distribution of the channeled beam and a uniform distribution of the nonsubstitutional tin in the sample. These assumptions are adequate in this experiment because the tin in cell walls exists as randomly oriented precipitates uncorrelated with the Si lattice. To present this information as a concentration-depth profile, we plot substitutional concentration (substitutional fraction times total concentration) instead of substitutional fraction. Because tin is a substitutional impurity in silicon, interface breakdown is indicated by a divergence of the total tin concentration vs depth and the substitutional tin concentration vs depth curves.

If TEM and ion channeling were equally sensitive to breakdown, they would both indicate breakdown at the same depth. This is rarely the case, however. The substitutional tin concentration falls below the total tin concentration at as much as a few tens of $\mathrm{nm}$ deeper than the point at which cells become visible in TEM, as is seen in Figs. 5 and 6. This indicates that there may be a time lag between when the interface first becomes unstable and when it is sufficiently deformed to give rise to visible cells. In practice, this is only a minor problem. For our samples, the concentration of substitutional tin changes little in the region between where ion 


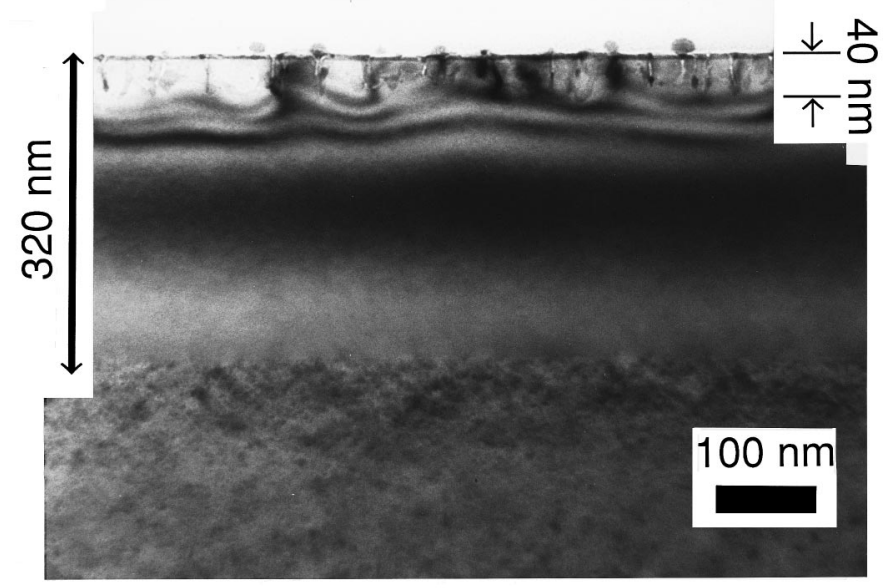

FIG. 5. Cross-sectional transmission electron micrograph of the sample having the tin concentration-depth profile of Fig. 6(a). The melt depth $(320 \mathrm{~nm})$ and breakdown depth $(40 \mathrm{~nm})$ marked here are the average of measurements on several micrographs of the same sample.

channeling indicates breakdown and where cells appear in TEM. The feature in the ion channeling spectra that correlates best with the appearance of cells is a drop in the concentration of substitutional tin (concentration is the same deeper and decreasing shallower), presumably because precipitates in the cell walls act as sinks for rejected solute.

When reading a concentration-depth profile to find the breakdown concentration, we use the average of (1) the flat or peak in substitutional concentration vs distance approaching the surface just before the substitutional concentration begins to drop and (2) the substitutional tin concentration where it diverges from the total concentration by more than $10 \%$. The ends of the error bars are the two different values used to compute the average. We prefer using the substitutional concentration instead of the total concentration because of RBS depth resolution effects. Samples with high implant doses have large surface peaks that are smeared over $30-40 \mathrm{~nm}$. The surface peak is entirely nonsubstitutional, and so there is little smearing in the substitutional concentration profile.

Pileup, counting statistics, and other errors inherent in spectrometry place a lower limit on the detectable breakdown concentration. The comparison between substitutional and total concentration is dominated by noise when the tin concentration is less than 0.05 at. $\%$ in the randomorientation spectrum and less than 0.1 at. $\%$ in the aligned spectrum. Consequently, ion channeling is not guaranteed to see breakdown at concentrations lower than about $0.2 \%$. Therefore, according to the theoretical neutral stability curve, at solidification velocities below $2 \mathrm{~m} / \mathrm{s}$, we can only rely on TEM to detect interface breakdown.

\section{RESULTS}

Figure 5 is a cross-sectional transmission electron micrograph of a typical sample. Next to the surface and extending to $40 \mathrm{~nm}$ depth is a band with high contrast caused by cell walls, strain around the cell walls, and other defects. Beyond
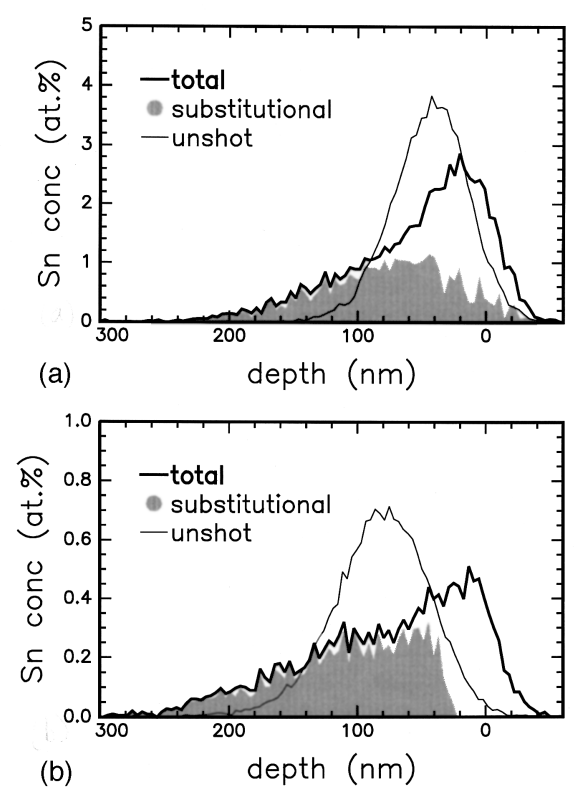

FIG. 6. Sn concentration-depth profiles before and after melting and solidification of a typical (a) high-implant-dose sample held at room temperature and (b) low-implant-dose sample preheated with a $\mathrm{CO}_{2}$ laser prior to melting. Table IV gives the experimental parameters. The thin line shows the implanted profile measured on a companion sample (because laser melting after RBS may damage the sample) scaled vertically to give the same area as the total tin profile. The thick line is the total concentration of tin as calculated from the random spectrum. The shaded region is the concentration of substitutional tin calculated using Eq. (6).

that is an even colored band extending to a depth of $320 \mathrm{~nm}$. This is a silicon-tin solution that has few defects and is epitaxial to the silicon underneath. The cloudy region near the bottom of the micrograph is the unmelted silicon substrate. The cloudiness is due to vacancy loops left over from the boron implant.

The concentration-depth profile obtained by RBS and ion channeling for the sample of Fig. 5 is shown in Fig. 6(a). All displayed depth profiles appear artificially broadened by a Gaussian detector resolution function of roughly 30-40 nm FWHM; "true", depth profiles, when necessary, can be obtained by deconvoluting this Gaussian from the displayed profiles as in Ref. 11. For our purposes this is not necessary because the only features that are affected significantly are spatial variations in the depth profile that are large over distances comparable to the detector resolution; the features that interest us vary more slowly with depth. We determine the breakdown concentration two ways. First, having observed the appearance of cell walls at $40 \mathrm{~nm}$ depth using TEM, we note that this corresponds to the boundary of a flat region $(100-40 \mathrm{~nm})$ of the profile. The substitutional concentration here is about $1 \%$. Second, we observe that the substitutional and total concentrations differ by $10 \%$ at $90 \mathrm{~nm}$ depth where the tin concentration is $1.1 \%$. These two values define the error bar for concentration, and the average is used to plot the data point (note that for this sample, the symbol drawn in Fig. 7 is larger than the error bar). The data are summarized in Table IV. We determine the velocity to be $3.1 \mathrm{~m} / \mathrm{s}$, using 
TABLE IV. Selected experimental results.

\begin{tabular}{|c|c|c|c|c|}
\hline Quantity & Units & Method & $\begin{array}{l}\text { Sample of } \\
\text { Fig. 6(a) }\end{array}$ & $\begin{array}{l}\text { Sample of } \\
\text { Fig. 6(b) }\end{array}$ \\
\hline Tin implant: dose & ions $/ \mathrm{cm}^{2}$ & RBS & $3.5 \times 10^{15}$ & $3 \times 10^{15}$ \\
\hline Energy & $\mathrm{keV}$ & - & 120 & 165 \\
\hline Melt duration & ns & Surface reflectivity & 139 & 143 \\
\hline Solidification velocity & $\mathrm{m} / \mathrm{s}$ & Simulation & 3.1 & 3.2 \\
\hline Maximum melt depth & $\mathrm{nm}$ & TEM & 320 & 350 \\
\hline Breakdown depth & $\mathrm{nm}$ & TEM & 40 & 27 \\
\hline Breakdown depth & $\mathrm{nm}$ & Ion channeling & 70 & 50 \\
\hline Breakdown concentration & at. $\%$ & RBS & 1.05 & 0.3 \\
\hline Excimer laser fluence & $\mathrm{J} / \mathrm{cm}^{2}$ & & 1.25 & $\begin{array}{r}1.77 \text { after } 2 \\
\mathrm{CO}_{2} \text { lase }\end{array}$ \\
\hline
\end{tabular}

the measured melt duration and the calibration curve of Fig. 4.

Table IV also summarizes the data for the sample with the concentration-depth profile shown in Fig. 6(b). Whereas Fig. 6(a) was typical of a high implant dose of tin, Fig. 6(b) is typical of a low-implant-dose sample. For this sample, TEM shows cells at $27 \mathrm{~nm}$ where the substitutional tin concentration is about $0.3 \%$. As in Fig. 6(a), the substitutional tin concentration has been steady at this value for several tens of $\mathrm{nm}$ and declines as depth decreases. The substitutional and total concentrations diverge by $10 \%$ in the middle of the plateau. For both samples, cells appear in the electron micrograph at shallower depths than where the total tin concentration diverges from the substitutional tin concentration. Plan view TEM on a sample similar to these (implanted with 1 $\times 16 \mathrm{~cm}^{-2}$ tin at $165 \mathrm{keV}$, melted by a $\mathrm{XeCl}$ laser without $\mathrm{CO}_{2}$ laser heating, velocity of $4.3 \mathrm{~m} / \mathrm{s}$ ) indicates that the typical cell diameter is $60 \mathrm{~nm}^{49}$

In Fig. 7 we plot of data for all samples and several calculations of the neutral stability curve. Two calculations of the cellular branch of the neutral stability curve (full nonequilibrium and local equilibrium) shown in Fig. 7 use the highest and lowest literature values of interfacial tension. Both values produce curves that pass through the data.

\section{DISCUSSION}

For the velocity range of our experiments, the important experimental parameters are those in the nonequilibrium form of the absolute stability limit, Eq. (1). Solidification velocity and breakdown concentration are measured, and all other parameters are obtained from the literature. Because we compare our data to a theory that has no adjustable parameters, the usefulness of the comparison depends on the accuracy of the input parameters. Some parameters are well established, such as the melting point of pure solvent, $T_{M},{ }^{36}$ and the latent heat, which are needed for the capillarity constant $\Gamma{ }^{36}$ For the interfacial tension, which is also needed to calculate $\Gamma$, we used the value found from the interpretation of nucleation experiments ${ }^{39-41}$ extrapolated ${ }^{40,41}$ to zero undercooling. Parameters for the dilute solution, equilibrium partition coefficient, and equilibrium liquidus slope were obtained from the equilibrium phase diagram. ${ }^{37}$ Laser melting and solute trapping experiments that we have reported previously $^{33}$ give $v_{D}$ [needed for Eq. (2)] and $D$, thereby providing the rest of $m(v)$. Given these parameters, Eq. (1) reduces to concentration as a function of velocity. The full Mullins-Sekerka analysis required thermal parameters too. While good values for these parameters are also available, the predictions become independent of the thermal parameters as the system approaches the absolute stability limit. Values for all the parameters are given in Table I.

Of the parameters that go into the calculated neutral stability curve, the interfacial tension is the most uncertain. Three different values are tabulated in Table I. The calculations of Huntley and Davis ${ }^{28}$ and Brunco ${ }^{11}$ presented in Fig.1 use a value of interfacial tension ${ }^{39}$ that is now out of date. Recent results by Shao and Spaepen ${ }^{40}$ and Li and Herlach ${ }^{41}$ indicate that the value for interfacial tension (at $T_{M}$ ) is higher. Because interfacial tension is measured in nucleation experiments, reported values are, strictly speaking, only lower bounds on the interfacial tension: the value could still be revised upwards. Such improvements are not helpful if the interfacial tension is sufficiently anisotropic. The theory for interface stability requires the interfecial tension of a par-

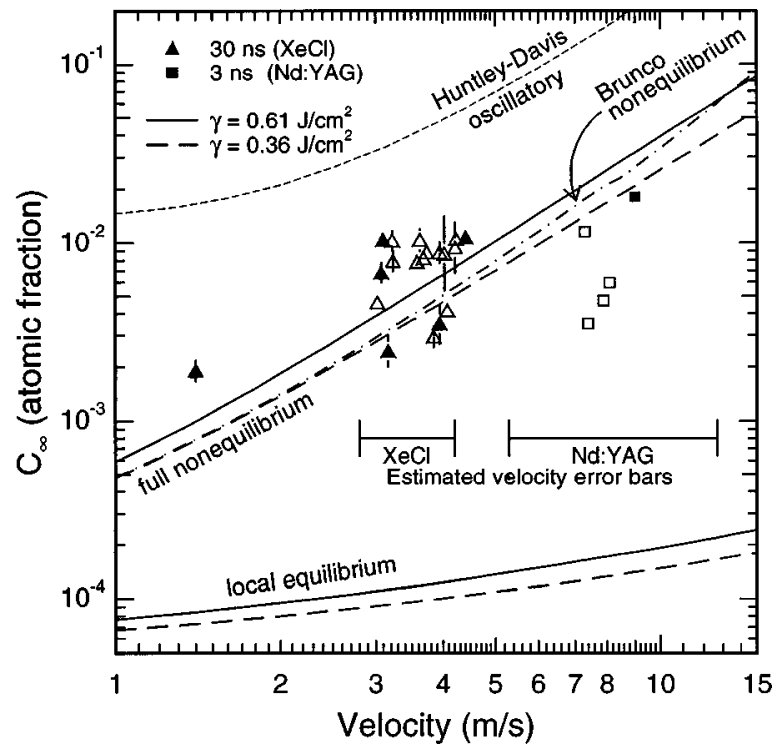

FIG. 7. Comparison of data to theoretical neutral stability curves for Si-Sn (001). The solid symbols mark those samples that were analyzed by TEM. 


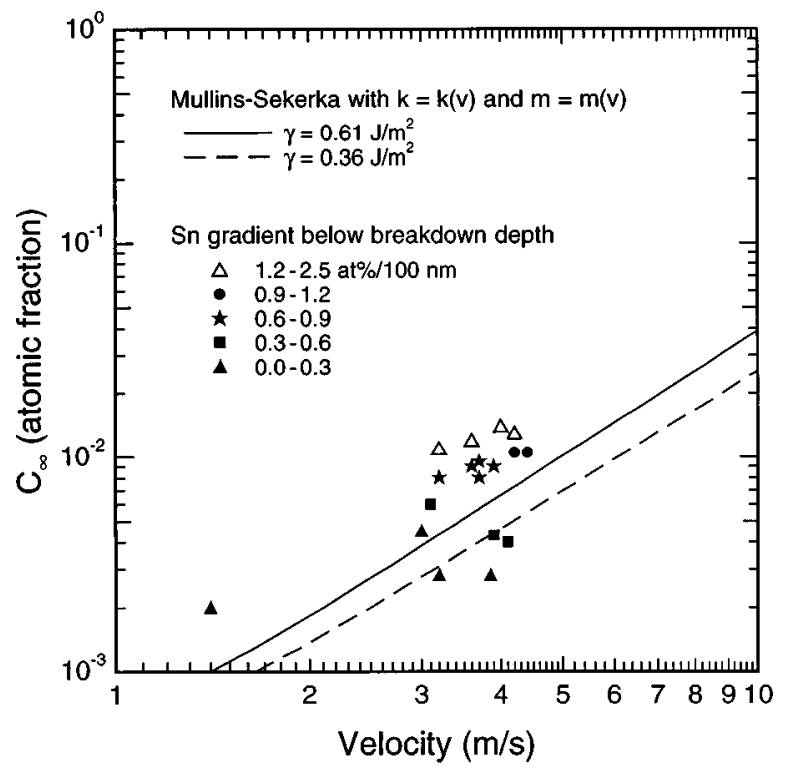

FIG. 8. Breakdown concentration vs velocity for XeCl-melted (001)-oriented samples grouped by gradient in total tin concentration in the solid below the breakdown depth. Lower gradients are better approximations of steady-state conditions.

ticular orientation, $\{001\}$ in the case of Fig. 7. This orientation is expected to have among the highest interfacial tensions. Nucleation experiments measure an average interfacial tension. The average should be lower than the value for $\{001\}$; it may even be dominated by the minimum value expected for $\{111\}$. Also, there is no measure of the effect of tin and boron on interfacial tension. Preferential solute segregation to the interface will reduce the interfacial tension.

The data of Fig. 7 show scatter, but there are some patterns. First, for all samples, the amount of tin in solution exceeds the maximum equilibrium solubility of tin in silicon [an atomic fraction of $10^{-3}$ at $1339 \mathrm{~K}$ (Ref. 51)]. Second, all

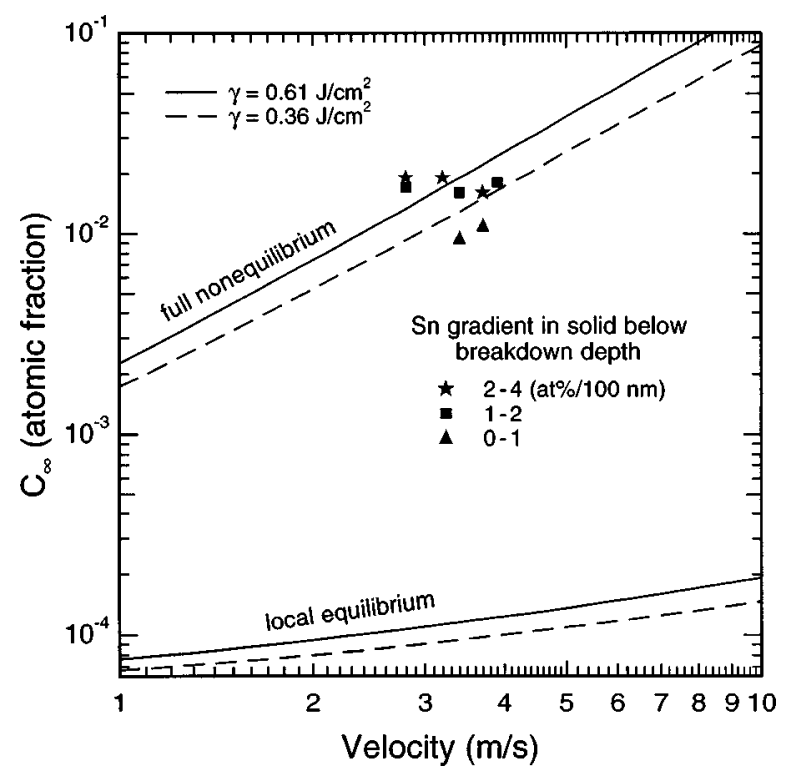

FIG. 9. Breakdown concentration vs velocity for XeCl-melted (111)-oriented samples grouped by gradient in total tin concentration in the solid below the breakdown depth. Lower gradients are better approximations of steady-state conditions. data points lie well above the neutral stability curve calculated under an assumption of local equilibrium (nearly flat at $C_{\infty} \approx 10^{-4}$ ). Nonequilibrium effects strongly stabilize the solid-liquid interface; the steady-state nonequilibrium theory has some merit because it correctly predicts the large increase in breakdown concentration.

The third observation is that most data points lie above the theoretical neutral stability curve. There are two potential reasons why we might expect to observe such a trend in our experiments. First, our experiment is not, strictly speaking, steady state. The diffusion of rejected solute in the boundary layer away from the interface is superposed on a background of long-range diffusion away from the implant peak. At depths greater than the implant peak, the superposition reduces the magnitude of the solute gradient in the liquid at the interface relative to its true steady-state value with the same interface velocity, partition coefficient, and solute concentration in the solid. The result is a relative reduction in the amount of constitutional supercooling. This effect matters most at the lower velocities where the constitutional supercooling mechanism plays a significant role: as velocity increases, the neutral stability criterion approaches the absolute stability asymptote where solute redistribution is limited by the time available instead of the steepness of the gradient. Second, we cannot observe infinitesimal perturbations. There is a delay between the time when the interface first becomes unstable and when it becomes sufficiently deformed to alter the microstructure observably. Substantial precipitation may only occur in the presence of a highly deformed interface.

The data have been analyzed to examine the importance of deviations from steady state. The flat region in the concentration-depth profile of Fig. 6(b) indicates a good approximation of steady state prior to breakdown. Not all concentration-depth profiles show a flat region, however. The data of Fig. 8 are grouped according to the gradient of the total tin concentration in the solid in the $100 \mathrm{~nm}$ leading up to breakdown. This should scale with the far-field gradient in the liquid (upon which is superposed the diffusional boundary layer), but the gradient in the liquid cannot be measured. The results for (111) silicon, shown in Fig. 9, are similar. The trend is clear: as the gradient increases, more $\mathrm{Sn}$ can be incorporated before breakdown is observed and the data points appear further up on the plot. We conclude that transient effects play a significant role in interfacial breakdown in rapid solidification and, possibly, in slow solidification as well. Theories incorporating the transient effects discussed above in a quantitative manner are needed to describe interface breakdown in realistic scenarios. Initial steps addressing some of these issues have been taken by Brunco, ${ }^{11}$ Coriell et al., ${ }^{52}$ Ludwig et al., ${ }^{53}$ and Warren and Langer. ${ }^{54}$

\section{SUMMARY}

(1) Nonequilibrium solidification effects substantially stabilize the planar solid-liquid interface against cellular breakdown. Supersaturations of up to 10 times the maximum equilibrium solubility were obtained by rapid solidification. The critical solute concentration to induce breakdown is roughly 100 times that predicted by linear stability theory with local interfacial equilibrium. 
(2) The results agree well with linear stability theories incorporating a velocity-dependent partition coefficient and kinetic liquidus slope, with no free parameters.

(3) In the velocity and concentration regime amenable to experiment, Huntley and Davis's predictions ${ }^{28}$ and Brunco's ${ }^{11}$ are virtually indistinguishable.

(4) The ability of steady-state theories to fully account for our results is limited because they do not address potential effects of deviations from steady state. We observe a systematic increase of the breakdown concentration with increasing deviation from steady-state conditions, parametrized by the concentration gradient in the solid just prior to breakdown.

\section{ACKNOWLEDGMENTS}

This research was supported by the U.S. Department of Energy under Contract Nos. DE-FG02-89ER45401 and DEFG05-92ER79127. We are grateful to Yuan Lu for performing plan view TEM and assisting with the cross-sectional TEM; to David Brunco for valuable discussions, calculating and sharing his theoretical predictions for the silicon-tin system, and practical help with the Nd:YAG laser; and to Douglas Huntley for calculating and sharing his theoretical predictions for the silicon-tin system. Ion implantation was performed at the Surface Modification and Characterization facility at Oak Ridge National Laboratory.

*Electronic address: maziz@ @arvard.edu

${ }^{1}$ C. W. White, S. R. Wilson, B. R. Appleton, and F. W. Young, Jr., J. Appl. Phys. 51, 738 (1980).

${ }^{2}$ P. Baeri, J. M. Poate, S. U. Campisano, G. Foti, E. Rimini, and A. G. Cullis, Appl. Phys. Lett. 37, 912 (1980)

${ }^{3}$ A. G. Cullis, D. T. J. Hurle, H. C. Webber, N. G. Chew, J. M. Poate, P. Baeri, and G. Foti, Appl. Phys. Lett. 38, 642 (1981).

${ }^{4}$ E. P. Fogarassy, D. H. Lowndes, J. Narayan, and C. W. White, J. Appl. Phys. 58, 2167 (1985).

${ }^{5}$ S. U. Campisano and J. M. Poate, Appl. Phys. Lett. 47, 485 (1985).

${ }^{6}$ R. Reitano, P. M. Smith, and M. J. Aziz, J. Appl. Phys. 76, 1518 (1994).

${ }^{7}$ M. J. Aziz, Metall. Mater. Trans. A 27, 671 (1996).

${ }^{8}$ S. Lombardo, K. Kramer, Michael O. Thompson, and Duane R. Smith, Appl. Phys. Lett. 59, 3455 (1991).

${ }^{9}$ C. W. White, D. M. Zehner, J. Narayan, O. W. Holland, B. R. Appleton, and S. R. Wilson, in Laser-Solid Interactions and Transient Thermal Processing of Materials, edited by $\mathrm{J}$. Narayan, W. L. Brown, and R. A. Lemons, MRS Symposium Proceedings No. 13 (Materials Research Society, Pittsburgh, 1983), p. 287.

${ }^{10}$ A. G. Cullis, J. Vac. Sci. Technol. B 1, 272 (1983).

${ }^{11}$ D. P. Brunco, Ph.D. thesis, Cornell University, 1995.

${ }^{12}$ D. P. Brunco, Michael O. Thompson, D. E. Hoglund, and M. J. Aziz, in Joining and Adhesion of Advanced Inorganic Materials, edited by A. H. Carim, D. S. Schwartz, and R. S. Silberglitt, MRS Symposia Proceedings No. 314 (Materials Research Society, Pittsburgh, 1993), p. 653.

${ }^{13}$ W. A. Tiller, K. A. Jackson, R. W. Rutter, and B. Chalmers, Acta Metall. 1, 428 (1953).

${ }^{14}$ W. W. Mullins and R. F. Sekerka, J. Appl. Phys. 35, 444 (1964).

${ }^{15}$ J. C. Baker and J. W. Cahn, Acta Metall. 17, 575 (1969).

${ }^{16}$ J. Narayan, J. Cryst. Growth 59, 583 (1982).

${ }^{17}$ W. J. Boettinger, S. R. Coriell, and R. Trivedi, in Rapid Solidification Processing: Principles and Technologies IV, edited by $\mathrm{R}$. Mehrabian and P. A. Parrish (Claitor's Publishing Division, Baton Rouge, LA, 1988), p. 13.

${ }^{18}$ M. J. Aziz, M. O. Thompson, P. S. Peercy, and C. W. White, Phys. Rev. Lett. 56, 2489 (1986).

${ }^{19}$ G. J. Galvin, J. W. Mayer, and P. S. Peercy, Appl. Phys. Lett. 46, 644 (1985).

${ }^{20}$ M. O. Thompson, P. H. Bucksbaum, and J. Bokor, in Energy Beam-Solid Interactions and Transient Thermal Processing, edited by D. K. Biegelsen, G. A. Rezgonyi, and C. V. Shank, MRS

Symposia Proceedings No. 35 (Materials Research Society, Pittsburgh, 1985), p. 181.

${ }^{21}$ B. C. Larson, J. Z. Tischler, and D. M. Mill, J. Mater. Res. 1, 144 (1986).

${ }^{22}$ J. A. Kittl, M. J. Aziz, D. P. Brunco, and M. O. Thompson, Appl. Phys. Lett. 64, 2359 (1994).

${ }^{23}$ M. J. Aziz and C. W. White, Phys. Rev. Lett. 75, 2675 (1986).

${ }^{24}$ L. M. Goldman and M. J. Aziz, J. Mater. Res. 2, 524 (1987).

${ }^{25}$ M. J. Aziz and T. Kaplan, Acta Metall. 26, 2335 (1988).

${ }^{26}$ M. J. Aziz and W. J. Boettinger, Acta Metall. 42, 527 (1994).

${ }^{27}$ G. J. Merchant and S. H. Davis, Acta Metall. Mater. 38, 2683 (1990).

${ }^{28}$ D. A. Huntley and S. H. Davis, Acta Metall. Mater. 41, 2025 (1993).

${ }^{29}$ S. R. Coriell and R. F. Sekerka, J. Cryst. Growth 61, 499 (1983).

${ }^{30}$ J. W. Cahn, in Japan-US Joint Seminar on Solidification of Metals and Alloys, edited by K. Gunji, J. Kaneko, and T. Umeda (Japan Society of Promotion of Science, Tokyo, 1977), p. 1.

${ }^{31}$ J. Galvin, J. W. Mayer, and P. S. Peercy, Appl. Phys. Lett. 46, 644 (1985).

${ }^{32}$ B. C. Larson, J. Z. Tischler, and D. M. Mills, in Fundamentals of Beam-Solid Interactions and Transient Thermal Processing, edited by M. J. Aziz, L. E. Rehn, and B. Stritzker, MRS Symposia Proceedings No. 100 (Materials Research Society, Pittsburgh, 1988), p. 513.

${ }^{33}$ D. E. Hoglund, M. J. Aziz, S. R. Stiffler, M. O. Thompson, J. Y. Tsao, and P. S. Peercy, J. Cryst. Growth 109, 107 (1991).

${ }^{34}$ J. Narayan, R. B. James, O. W. Holland, and M. J. Aziz, J. Vac. Sci. Technol. A 3, 1836 (1985).

${ }^{35}$ C. Y. Ho, R. W. Powell, and P. E. Liley, J. Phys. Chem. Ref. Data Suppl. 3, 394 (1971).

${ }^{36}$ R. Hultgren, P. D. Desai, D. T. Hawkins, M. Gleiser, K. K. Kelley, and D. D. Wagman, Selected Values of the Thermodynamic Properties of the Elements (American Society for Metals, Metals Park, OH, 1973).

${ }^{37}$ C. D. Thurmond and M. Kowalchik, Bell Syst. Tech. J. 39, 169 (1960).

${ }^{38}$ Y. S. Touloukian, Thermophysical Properties of Matter: The Thermophysical Properties Research Center Data Series (IFI/ Plenum, New York, 1970-1979), pp. 205 and 339.

${ }^{39}$ P. V. Evans and S. R. Stiffler, Acta Metall. 39, 2727 (1991).

${ }^{40}$ Y. Shao and F. Spaepen, J. Appl. Phys. 79, 2981 (1996).

${ }^{41}$ D. Li and D. Herlach, Europhys. Lett. 34, 423 (1996).

${ }^{42}$ E. P. Donovan, F. Spaepen, D. Turnbull, J. M. Poate, and D. C. 
Jacobson, Appl. Phys. Lett. 42, 698 (1983).

${ }^{43}$ G. E. Jellison, Jr., in Pulsed Laser Processing of Semiconductors, Semiconductors and Semimetals, Vol. 23, edited by R. F. Wood, C. W. White, and R. T. Young (Academic, New York, 1984), Chap. 3.

${ }^{44}$ E. D. Palik, Handbook of Optical Constants of Solids II (Academic, Boston, 1991).

${ }^{45}$ T. Papa, F. Scudieri, M. Marinelli, U. Zammit, and G. Cembali, J. Phys. (Paris), Colloq. 44, C5/73 (1983).

${ }^{46}$ M. J. Aziz, C. W. White, J. Narayan, and B. Stritzker, Energy Beam-Solid Interaction and Transient Thermal Processing IV (Editions de Physique, Paris, France, 1985), p. 231.

${ }^{47}$ G. E. Jellison, F. A. Modine, C. W. White, R. F. Wood, and R. T.
Young, Phys. Rev. Lett. 46, 1414 (1985).

${ }^{48}$ J. A. Kittl, R. Reitano, M. J. Aziz, D. P. Brunco, and M. O. Thompson, J. Appl. Phys. 73, 3725 (1993).

${ }^{49}$ D. E. Hoglund, Ph.D. Thesis, Harvard University, 1996.

${ }^{50}$ L. C. Feldman, J. W. Mayer, and S. T. Picraux, Materials Analysis by Ion Channeling (Academic, New York, 1982), p. 59.

${ }^{51}$ T. B. Massalski, Binary Alloy Phase Diagrams (American Society for Metals, Metals Park, OH, 1986).

${ }^{52}$ S. R. Coriell, R. F. Boisvert, B. F. McFadden, L. N. Brush, and J. J. Favier, J. Cryst. Growth 140, 139 (1994).

${ }^{53}$ A. Ludwig, K. Greven, and P. R. Sahm, J. Cryst. Growth 186, 291 (1998).

${ }^{54}$ J. A. Warren and J. S. Langer, Phys. Rev. E 47, 2702 (1993). 